\title{
Sustained Transmitter Output by Increased Transmitter Turnover in Limb Muscles of Old Mice
}

\author{
S. S. Kelly ${ }^{1}$ and N. Robbins \\ Department of Developmental Genetics and Anatomy, School of Medicine, Case Western Reserve University, \\ Cleveland, Ohio 44106
}

The ability of neuromuscular junctions in old animals to maintain tetanic output was tested in phasic and tonic limb muscles and the physiologic mechanism of maintenance was elucidated by analysis of the turnover of a false transmitter during prolonged tetani. Transmitter release during and after tetani was compared in limb muscles of young (8-9 month) and old (2830 month) male CBF-1 mice. Amplitudes of end-plate potentials (epp's) in curarized preparations and of spontaneous miniature end-plate potentials (mepp's) were measured in vitro at $30^{\circ} \mathrm{C}$ in soleus and extensor digitorum longus (edl) muscles.

In both young and old soleus muscles, epp amplitude was maintained at about $45 \%$ of resting level during the latter part of trains of 1200 stimuli at $10 \mathrm{~Hz}$ but recovered to about $90 \%$ control within a few seconds after stimulation ceased. In edl muscles of young mice, epp amplitudes during a $20 \mathrm{~Hz}$ train of 1200 impulses steadily declined to about $20 \%$ of control and gradually recovered over $2 \mathrm{~min}$ after the tetanus. In old edl muscles, tetanic decay of the epp's was greater and recovery slower than in young muscles, but absolute epp amplitudes were invariably greater.

During trains of 6000 impulses at $10 \mathrm{~Hz}$, plateau epp amplitude decayed to $40-50 \%$ in young soleus muscle and $30-40 \%$ control in old muscle, but recovery was similar and absolute epp amplitudes were greater in old soleus muscle. A false transmitter precursor, homocholine $(\mathrm{HoCh})$, was used to investigate the mechanism of this prolonged output, and, therefore, the use of $\mathrm{HoCh}$ in this system was first validated. Radiolabeled $\mathrm{HoCh}$ was taken up and concentrated at the end-plate region, and label was released upon nerve stimulation just as in the case of radiolabeled choline. Unlabeled HoCh partially reduced uptake of labeled choline. Acetyl-HoCh but not $\mathrm{HoCh}$ produced postsynaptic depolarization.

In the presence of $50 \mu \mathrm{M} \mathrm{HoCh}$, there was substantial rundown of epp amplitude in young soleus muscle during a $10 \mathrm{~Hz}$ / 6000 pulse tetanus and recovery was incomplete. Amplitudes of mepp's in similarly tetanized noncurarized preparations showed a similar percentage of depression from pretetanic values. At the end of the tetanus, epp's were $20 \%$ of control in young muscle and $13 \%$ of control in old muscle. The maximum tetanic amplitude reduction (compared to that without $\mathrm{HoCh}$ ) was $80 \%$, and this was assumed to represent complete replacement of $\mathrm{ACh}$ by acetyl-HoCh in released quanta. When replacement of $\mathrm{ACh}$ by $\mathrm{HoCh}$ was formulated as an exponential, the decay rate con-

\footnotetext{
Received Nov. 15, 1985; revised Mar. 27, 1986; accepted Apr. 17, 1986.

This study was supported by a grant (USPHS AG00795) from the National Institute of Aging. The able technical assistance of Mrs. Valerie Young and Ms. Gretchen Bowling is gratefully acknowledged.

Correspondence should be addressed to Norman Robbins at the above address.

1 Present address: Department of Pharmaceutical Sciences, Aston University, The Triangle, Birmingham B4 7ET, England.

Copyright (C) 1986 Society for Neuroscience $0270-6474 / 86 / 102900-08 \$ 02.00 / 0$
}

stant in old soleus muscle was more than twice than that in young muscle.

In conclusion, in both tonic (soleus) and phasic (edl) limb muscles, with different patterns of tetanic epp rundown, the safety factor of transmission was not more compromised in old animals despite slightly greater percentage rundown in some instances. In addition, during tetanic firing, transmitter turned over more rapidly in old than in young junctions. As discussed, an increased output of quanta per impulse accounted for about half the accelerated turnover, and a smaller pool of available transmitter accounted for the remainder.

In soleus and extensor digitorum longus (edl) muscles of aging CBF-1 mice, 2 characteristics of the neuromuscular junction would lead to the prediction that transmitter release during tetani should either be compromised or require special mechanisms for maintenance of output. First, during short tetanic trains of 110 pulses, transmitter release appears to be about $70 \%$ greater in old than in young muscles (Banker et al., 1983). If this increase in output were sustained in longer trains, it would necessitate a substantial increase in transmitter synthesis and turnover. Second, old soleus and edl muscles show diminished numbers of synaptic vesicles and mitochondria (Fahim and Robbins, 1982), which might reduce the structural and metabolic support for sustained transmitter release and require faster transmitter turnover during tetani because of the smaller reservoir of available vesicles. For these reasons, we investigated transmitter release at physiologic frequencies in young and old mouse soleus and edl muscles during and after trains of 1200 impulses in order to assess fatigue and recovery in muscles with 2 different types of fatigue and in vivo firing patterns (see literature citations below). In addition, transmitter turnover was measured in the soleus muscle during longer trains of 6000 impulses. The soleus muscle, in contrast to diaphragm or phasic muscle (such as edl), lends itself to these studies because transmitter output in young animals is well maintained during long trains in vitro (Gertler and Robbins, 1978; Robbins and Fischbach, 1971) and in vivo (Fischbach and Robbins, 1969; Hnik et al., 1978).

In assessing transmitter turnover, the use of hemicholinium (as per Elmqvist and Quastel, 1965) was precluded by the preliminary findings in soleus muscle of rapid recovery of transmitter release after tetani despite continued presence of the drug. Therefore, we used physiologic analysis of false transmitter release to study transmitter turnover (cf. Colquhoun et al., 1977). The choline analog, 3-trimethylamino-propan-1-ol (homocholine), was chosen for this purpose because there is extensive biochemical information on its uptake, acetylation, and release (for a review, see Collier and Kwok, 1982), especially in the electromotor system of Torpedo, a synapse homologous to the neuromuscular junction (Luqmani et al., 1980). Studies were done to confirm that homocholine was also treated as a trans- 
mitter precursor in the mouse soleus. In the same muscle, it was found by use of homocholine that in the aged mouse, the safety factor of transmitter release is well maintained during long tetani by a mechanism involving accelerated transmitter turnover.

\section{Materials and Methods}

Male CBF-1 mice (CB6F, BALB/cNNia $\times$ c57BL/6NNia; Charles River Breeding Laboratory) were used in 2 age groups (except where indicated otherwise): 8-9 months (young mature) and 28-30 months (old). Mice with weight loss, ankylosed joints, or gross organ pathology were not used (see Fahim and Robbins, 1982). The edl and soleus muscles were removed from animals under methoxyflurane (Pitman-Moore) anesthesia and were pinned onto Silgard 184 (Dow Corning) in Krebs saline (pH 7.2) oxygenatcd with $95 \% \mathrm{O}_{2}-5 \% \mathrm{CO}_{2}$. The composition of the saline was (mM): $\mathrm{NaCl}, 135 ; \mathrm{KCl}, 5 ; \mathrm{NaH}_{2} \mathrm{CO}_{3}, 15 ; \mathrm{Ca}$ gluconate, 2.5; $\mathrm{MgSO}_{4}, 1 ; \mathrm{Na}_{2} \mathrm{HPO}_{4}, 1$; glucose, 11 . In order to record end-plate potentials (epp's), $1.8 \mu \mathrm{g} / \mathrm{ml}(+)$-tubocurarine chloride (curare) was added to the saline, and the muscles were allowed to equilibrate with the curare solution for at least $1 \mathrm{hr}$ before epp's were recorded. When the effects of the false transmitter precursor, HoCh, were being investigated, muscles were allowed to equilibrate in curare-Krebs solution containing $0.05 \mathrm{~mm}$ HoCh for at least $1 \mathrm{hr}$ before recording. HoCh was generously supplied to us by Dr. Sharon Welner from the laboratory of Dr. Brian Collier (McGill University). Choline "recovery" solutions contained 0.1 $\mathrm{mM}$ choline in curare-Krebs saline.

\section{Electrophysiological recordings}

Muscles were placed in a Perspex chamber through which oxygenated curare-Krebs at $30.0 \pm 0.5^{\circ} \mathrm{C}$ flowed at a rate of $10-15 \mathrm{ml} / \mathrm{min}$. Glass capillary microelectrodes filled with $2 \mathrm{M}$ potassium citrate (15-20 M $\Omega$ resistance) were inserted into muscle fibers at the end-plate region. In order to record epp's, the nerve attached to the muscle was stimulated via a suction electrode using a WPI $302 \mathrm{~T}$ digital stimulator and stimulus isolation unit. Stimuli were $50 \mu \mathrm{sec}$ in duration and ca. 5 times threshold intensity. The epp's, monitored on a Tektronix 5111A storage oscilloscope via a WPI M707 preamplifier, were only recorded if the risetime was less than $1 \mathrm{msec}$.

Both evoked potentials and resting membrane potentials (rmp's) were sampled via an analog-to-digital converter (10 kHz sampling rate) and analyzed on-line using a Northstar Horizon microcomputer. The baseline, peak, rise-time, and time to half-decay of each epp were also stored on floppy disks. Amplitudes of epp's were corrected for nonlinear summation (Martin, 1955), using a reversal potential of $-15 \mathrm{mV}$, and to a standard rmp of $-80 \mathrm{mV}$ (Banker et al., 1983). The raw data (epp's during tetani) were similar in appearance to those previously published by one of us (Robbins and Fischbach, 1971) and are therefore not supplied here.

\section{Stimulation and recording protocols}

Two basic stimulation protocols were used. In the first, 25-30 "control" epp's $(0.5 \mathrm{~Hz})$ were recorded followed by 1200 epp's at $10 \mathrm{~Hz}$ (soleus) or $20 \mathrm{~Hz}$ (edl), and these in turn were followed by 60 "recovery" epp's at $0.5 \mathrm{~Hz}$. The mean amplitude of the control epp's and of groups of $40-50$ high-frequency epp's, sampled at $30 \mathrm{sec}$ (soleus) or $15 \mathrm{sec}$ (edl) intervals, was calculated. Amplitudes of the first 10 epp's of trains ("rundown" epp's) were not included in these calculations. Individual values for the amplitudes of the first 10 recovery epp's were used, followed by the means of groups of 5 epp's at intervals thereafter.

The second stimulation protocol, used only on soleus, was the same as the first, except that 6000 epp's were elicited at $10 \mathrm{~Hz}$ in the presence or absence of HoCh. In most cases, the samc muscle was used to record a long train in curare alone and also for the later long train in $\mathrm{HoCh}$, but only 1 long train in HoCh was obtained from each muscle. Preliminary experiments showed that epp amplitudes in a second long train in curare, $20 \mathrm{~min}$ after a previous train, were the same as in the first train, i.e., in curare alone, trains could be reproducibly repeated. In many cases (see Results) single epp's were recorded from several fibers before and after long trains of stimuli.

The epp amplitudes during or after tetani were also expressed as a percentage of the mean $0.5 \mathrm{~Hz}$ plateau epp amplitude in the same fiber so that depression and recovery of epp amplitude could be standardized between fibers and compared between muscles from young and old animals. Statistical significance of differences between groups of data werc calculated using Student's $t$ test.

To ensure that epp amplitudes during very long trains of stimuli did not decline to zero, but reached a plateau value in both curare alone and in $\mathrm{HoCh}$, soleus muscles from young mice were stimulated at 10 $\mathrm{Hz}$ for up to $45 \mathrm{~min}$. Recordings were made from several fibers before the long train, from 1 fiber up to $30 \mathrm{~min}$ of stimulation, and again from several fibers between 30 and $45 \mathrm{~min}$ of stimulation. In experiments with $\mathrm{HoCh}$, it was necessary to use signal averaging ( 20 epp's) to obtain accurate epp amplitudes after $15 \mathrm{~min}$ of stimulation.

\section{Evaluation of HoCh as a false transmitter precursor}

\section{Postsynaptic effect}

In order to determine whether acetyl-HoCh produces postsynaptic depolarization in soleus muscles from young mice, a $7 \mu \mathrm{M}$ concentration of each drug was applied to the muscles and the resulting end-plate depolarization was measured with intracellular electrodes. The drugs were applied by injecting $0.14 \mathrm{ml}$ of a $0.1 \mathrm{~mm}$ solution of drug into a tissue chamber containing $2 \mathrm{ml}$ of oxygenated Krebs. The drug was rapidly washed out of the chamber as soon as the depolarization reached a maximum, and at least $5 \mathrm{~min}$ was allowed to elapsed between successive applications. All the experiments were carried out at room temperature and after pretreatment of the muscles with $0.5 \mu \mathrm{M}$ ecothiopate (an irreversible inhibitor of AChE) and $0.2 \mu \mathrm{M}$ TTX to prevent spontaneous twitching. The same corrections (for rmp and nonlinear summation) were applied to the depolarization as were applied to epp's.

\section{Uptake}

Soleus muscles were rinsed 3-4 times over a period of $2.5 \mathrm{hr}$ in oxygenated Krebs solution at room temperature in order to remove endogenous extracellular choline. Next, the parameters for obtaining maximum twitches by nerve stimulation through suction electrodes were set. The muscles were then placed in Krebs solution containing ${ }^{14} \mathrm{C}$ $\mathrm{HoCh}$ (specific activity, $55 \mathrm{Ci} / \mathrm{mol}$; kindly provided by Dr. Brian Collier) with or without added unlabeled HoCh to give a final concentration of $50 \mu \mathrm{M} \mathrm{HoCh}$ in all cases. (+)-tubocurarine $(1.8 \mu \mathrm{g} / \mathrm{ml})$ was added in this and all following solutions, and the temperature was maintained at $30^{\circ} \mathrm{C}$. At the end of the $30 \mathrm{~min}$ preincubation in radioactive $\mathrm{HoCh}$, nerve stimulation at $10 \mathrm{~Hz}$ was begun for 8 out of every $10 \mathrm{~min}$ for 40 min. Finally, a room temperature washout with $20 \mathrm{ml}$ of Krebs at the end of the stimulation period was followed by further rinsing over $1 \mathrm{hr}$, a 30 min exposure to dimethoxy phosphoryl fluoride (DMPF, a cholinesterase inhibitor supplied by Dr. Peter Molenaar) and then another rinse and further soaking for $15 \mathrm{~min}$. At this point, the muscle was briefly placed on filter paper to remove excess moisture, the tendons were removed, and the muscle was separated into end-plate-containing (EP) and non-end plate (NEP) regions, both of which were weighed and frozen. For analysis, the muscles were homogenized in $0.3 \mathrm{M}$ acetic acid in ethanol, centrifuged at $3000 \mathrm{rpm}$ for $15 \mathrm{~min}$, and aliquots of the supernatant were removed for scintillation counting. To calculate endplate specific counts, counts per minute $(\mathrm{cpm}) / \mathrm{mg}$ wet weight of NEP were subtracted from that of EP, and the difference multiplied by the EP wet weight. Total NEP cpm was obtained by multiplying $\mathrm{cpm} / \mathrm{mg}$ wet weight of NEP times the sum of wet weights of EP and NEP regions. Similar experiments were also done with ${ }^{3} \mathrm{H}$-choline (New England $\mathrm{Nu}$ clear; $60-90 \mathrm{Ci} / \mathrm{mmol}$ at final concentration of $6 \mu \mathrm{Ci} / \mathrm{ml}$ ) instead of ${ }^{14} \mathrm{C}$ HoCh.

\section{Stimulation-induced release of radioactivity after loading with ${ }^{14} \mathrm{C}-\mathrm{HoCh}$}

After loading with ${ }^{14} \mathrm{C}-\mathrm{HoCh}$ and treatment with $\mathrm{DMPF}$ as described above, 2 soleus muscles (in the same $5 \mathrm{ml}$ compartment) were returned to Krebs solution at $30^{\circ} \mathrm{C}$ for two $15-20$ min periods, after which solutions were collected after each of two 20 min intervals. The muscles were then stimulated for $20 \mathrm{~min}$ at $10 \mathrm{~Hz}$, and the effluent was collected after an additional $5 \mathrm{~min}$ rest period. After 2 further $20 \mathrm{~min}$ collections, the muscle was analyzed for EP and NEP radioactivity as described above. Radioactive counts of aliquots of the effluents were expressed as $\mathrm{cpm} / \mathrm{min}$ of the collection period. Parallel experiments were done with ${ }^{3} \mathrm{H}$-choline instead of ${ }^{14} \mathrm{C}-\mathrm{HoCh}$ as the exogenous transmitter precursor. 


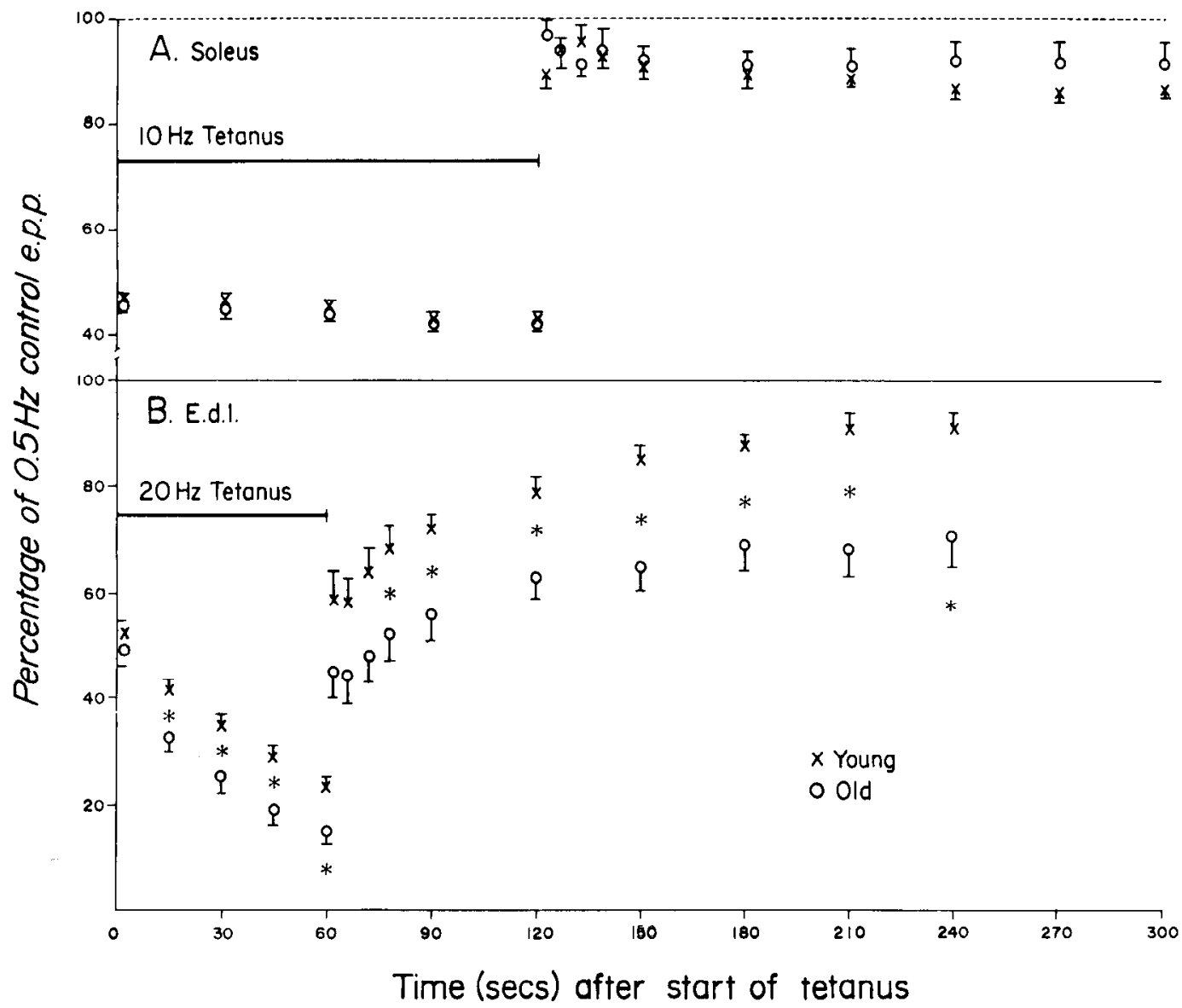

Figure 1. Decay and recovery of epp amplitudes during and after tetani in curarized soleus $(A)$ and edl $(B)$ muscles. Data are expressed as the percentage of pretetanus control amplitude in preparations stimulated at $0.5 \mathrm{~Hz}$. Each data point is the mean ( \pm SE) of 18-21 (soleus) or 8-13 (edl) fibers from 3-5 mice. For each fiber, 30-40 epp's during the tetanus were averaged for each value given, whereas during the first 30 sec of recovery, single epp values were obtained; thereafter, each time point represents an average of 5 epp's. Asterisk indicates significant $(p<0.05)$ difference between young and old.

\section{Results}

\section{Trains of 1200 epp's in curarized muscles}

After control epp's were obtained at $0.5 \mathrm{~Hz}$, the muscles were stimulated at either $10 \mathrm{~Hz}$ (soleus) or $20 \mathrm{~Hz}$ (edl). These stimulation frequencies were chosen to approximate the in vivo firing frequencies found in the equivalent rat muscles (Fischbach and Robbins, 1969). The epp's were recorded in groups of 40 at intervals during the tetanus (see Materials and Methods), beginning immediately after the initial rundown (first 10 epp's).

\section{Soleus}

During indirect stimulation at a frequency of $10 \mathrm{~Hz}$, the amplitude of the epp in soleus muscles from young mice fell within 10 epp's, to $47.3 \pm 0.7 \%$ (mean \pm SE of 21 fibers) of the 0.5 $\mathrm{Hz}$ control values (Fig. $1 A$ ). In muscles from old mice, the corresponding value was $46.2 \pm 1.4 \%(n=14)$. After 2 min of stimulation, there was a small further decrease in amplitude (ca. $5 \% ; p<0.05)$ in both young and old muscic. On return to a stimulation frequency of $0.5 \mathrm{~Hz}$, epp amplitudes recovered to control values within 2-4 sec. At no time was there a significant difference between young and old mice when values were expressed as a percentage of the $0.5 \mathrm{~Hz}$ control amplitude, although the absolute amplitudes were greater in old mice, as previously reported (Banker et al., 1983).

\section{Extensor digitorum longus}

When the frequency of indirect stimulation of young edl muscle was changed from $0.5 \mathrm{~Hz}$ to $20 \mathrm{~Hz}$, the epp amplitude decreased to $52.9 \pm 1.4 \%(n=13)$ of the control value within 10 epp's (Fig. $1 B$ ). The corresponding value in old animals, $48.9 \pm 2.8$ $(n=11)$, was not significantly different. After $1 \mathrm{~min}$ of stimulation at $20 \mathrm{~Hz}$, epp amplitude had decreased to $23.4 \pm 2.0 \%$ $(n=13)$ of $0.5 \mathrm{~Hz}$ control values in young muscles and to 15.1 $\pm 2.4 \%(n=11)$ in old animals. In both age groups, there was an initial fast partial recovery followed by a slower recovery phase. At all time points except the initial $20 \mathrm{~Hz}$ sample and during the first 6 sec of recovery, the values in old muscles, expressed as percentages of $0.5 \mathrm{~Hz}$ control, were significantly less than those in young muscles. However, because the initial absolute amplitude at $20 \mathrm{~Hz}$ in the old group $(1.28 \pm 0.09 \mathrm{mV}$, $n=20)$ was about twice that in the young $(0.65 \pm 0.08 \mathrm{mV}, n$ $=12$ ), the absolute amplitude at the end of tetanus was still larger in old than in young animals. The larger absolute epp amplitudes in old animals were due to increased transmitter release rather than to increased input resistance or receptor concentration (Banker et al., 1983).

\section{Trains of 6000 epp's in soleus}

\section{In the presence of curare only}

Transmitter release in edl muscle decayed to low lcvels after only $1 \mathrm{~min}$ of tetanic stimulation. Therefore, only soleus was used to study tetanic transmitter output over longer periods.

By the end of $10 \mathrm{~min}$ of nerve stimulation at $10 \mathrm{~Hz}$, epp amplitudes in young and old soleus muscles had decreased to $39.6 \pm 2.3 \%(n=11)$ and $31.3 \pm 1.5 \%(n=16)$, respectively, 


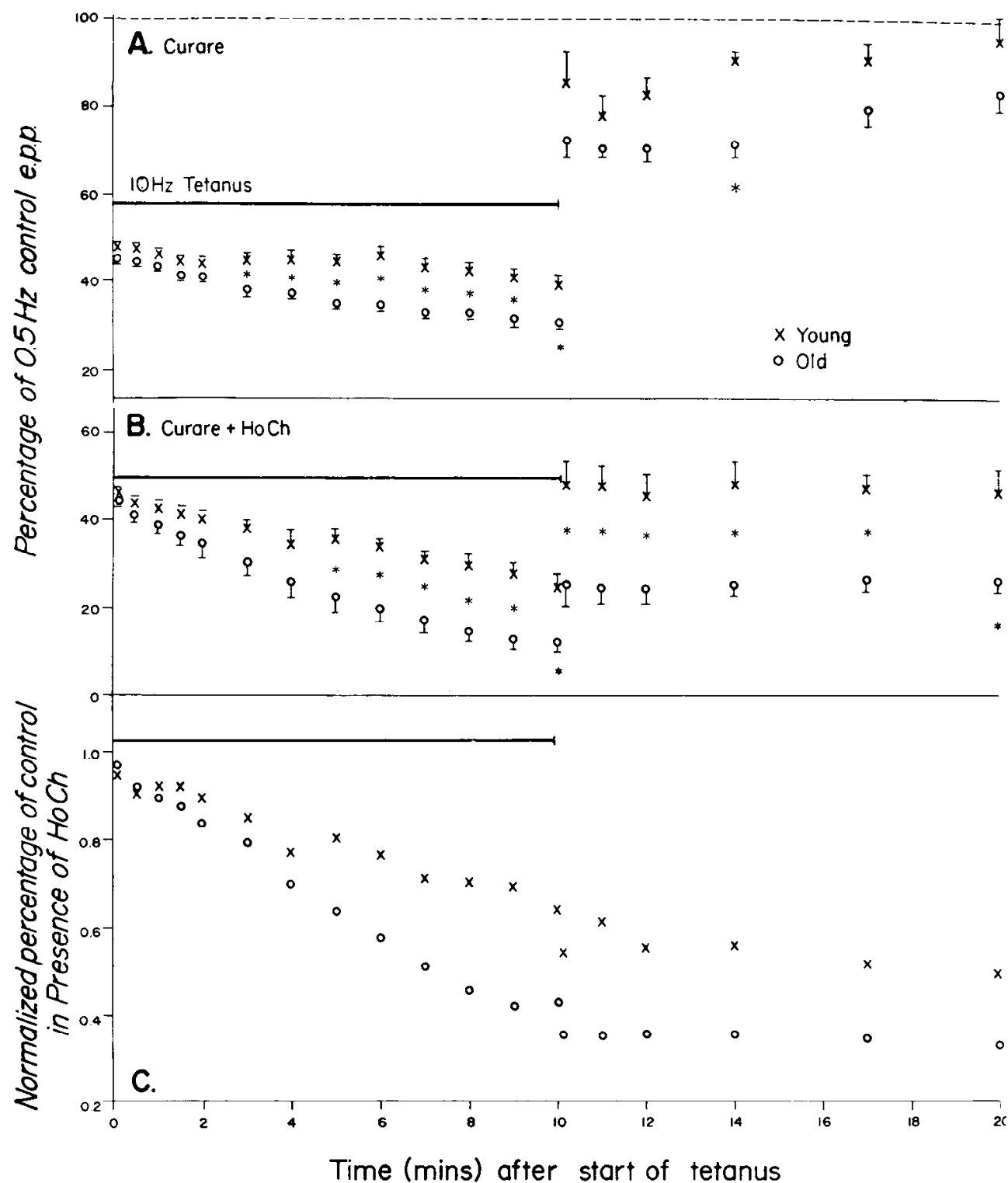

Figure 2. Decay and recovery of epp amplitude in curarized soleus muscle during and after a $10 \mathrm{~Hz}$ tetanus. Expression of data and symbols in $A$ (curare alone) and $B$ (curare $+50 \mu \mathrm{M}$ $\mathrm{HoCh}$ ) as in Figure 1. Data are means of 8-30 fibers in 5-7 mice in each age group. $C$, Mean values in $A$ and $B$ normalized (see text) to indicate percentage decay of epp due to the presence of HoCh. Note that in $A$ and $C$, ordinates do not begin al zero. of the initial $0.5 \mathrm{~Hz}$ control values. The relative epp depression during the $10 \mathrm{~Hz}$ tetani in old muscles was always significantly greater $(p<0.01)$ than in young muscles (Fig. $2 A$ ), but the difference was only about $10 \%$. Once again, absolute epp amplitudes were greater in old than in young animals because of the larger initial amplitudes (Table 1, row 1). In both age groups (with one exception), the valucs (relative to control) during recovery were the same, and a slow recovery phase was observed which was not present after the shorter trains of 1200 epp's (Fig. $2 A)$.

Transmitter turnover assessed by use of a false transmitter A physiologic assay of transmitter turnover using the false transmitter precursor, $\mathrm{HoCh}$, was used in young and old soleus muscles during long tetani. As a necessary preliminary step, a small number of experiments with radioactive tracers were carried out to confirm that HoCh had the same characteristics in mouse soleus as in the Torpedo electric organ, where more extensive work has established that $\mathrm{HoCh}$ is taken up, acetylated, and released in response to nerve stimulation (Luqmani et al., 1980). These and other experiments in which the postsynaptic responses to acetyl-HoCh $(\mathrm{AHoCh})$ and $\mathrm{ACh}$ were compared were necessary for the interpretation of the physiologic experiments described below.

\section{Characterization of the false transmitter}

In soleus muscles that were preincubated and then stimulated in ${ }^{14} \mathrm{C}-\mathrm{HoCh}$ (see Materials and Methods), the total end-platespccific uptake of $\mathrm{HoCh}$ accounted for $39 \%$ of the total muscle uptake ( $n=4$; range, $33-48 \%$ ). This result compared favorably with that in similar experiments with ${ }^{3} \mathrm{H}$-choline (see Materials and Methods), in which end-plate-specific uptake was $24 \%$ of the total $(n=6$; range, $18-37 \%)$. Furthermore, uptake of choline was reduced by $24 \%(n=4)$ when $50 \mu \mathrm{M}$ HoCh was present during the stimulation period. Nerve stimulation of muscles loaded with ${ }^{14} \mathrm{C}$-HoCh (see Materials and Methods) released radioactivity that was about $2-6$ times greater than prestimulation background release $(n=3$; example in Fig. $3 A)$, in good agreement with similar studies in Torpedo (Luqmani et al., 1980). For purposes of comparison, in experiments with ${ }^{3} \mathrm{H}$-choline, the ratio of stimulation-induced release to resting release of radioactivity varied from 1.5 to $2.3(n=3)$. Although these experiments do not distinguish between release of radioactive precursor or acetylated product, less than $3 \%$ of stimulation- 
Figure 3. A, Combined efflux of radioactivity from 2 combined young mouse soleus muscles after loading with ${ }^{14} \mathrm{C}-\mathrm{HoCh}$. Efflux is expressed as counts per minute (cpm) minus background per minute of collection period in order to compare collections of different durations. Horizontal bar indicates period of stimulation at 10 Hz. $B$, Intracellular recordings of depolarization at young soleus end plates produced by bath application of ACh (upper) and AHoCh (lower).

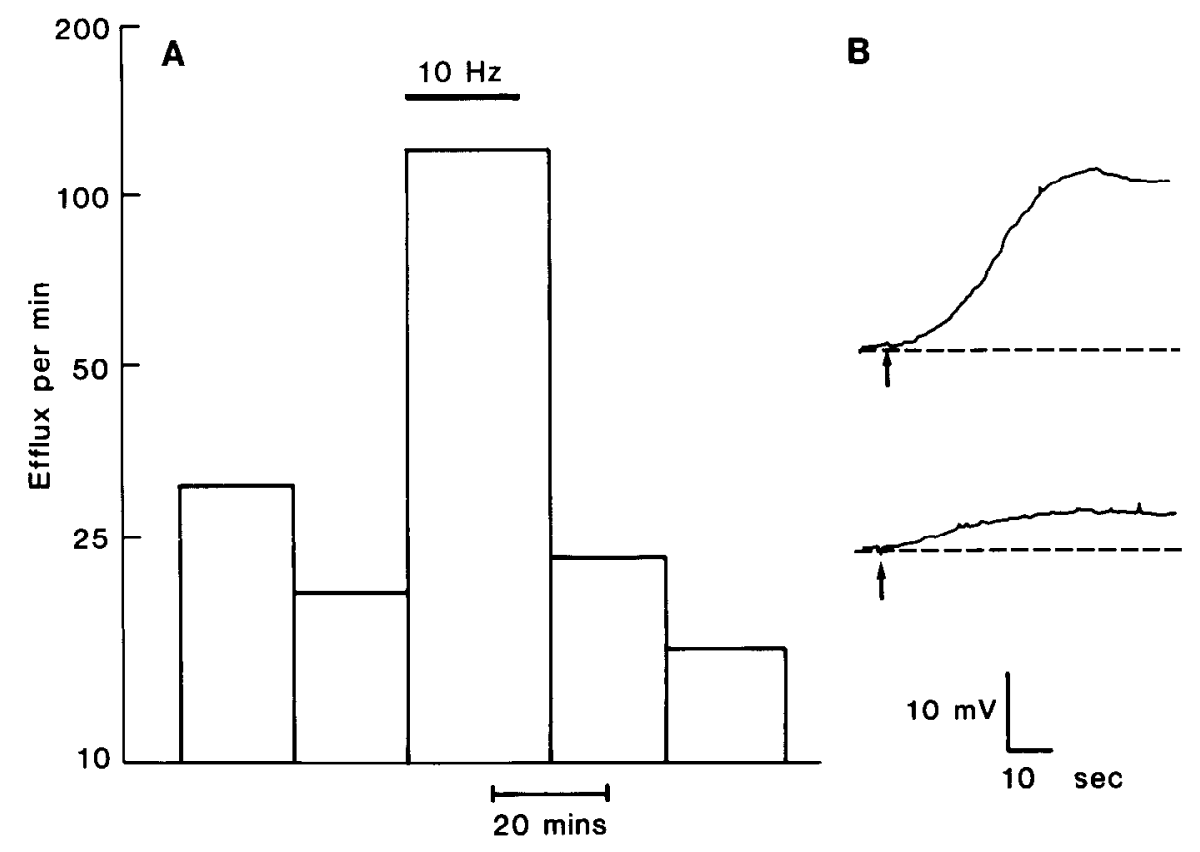

released radioactivity in Torpedo was nonacetylated $\mathrm{HoCh}$ (Luqmani et al., 1980). It is unlikely that this was different in soleus muscle given the above similarities in the 2 systems between uptake and release of $\mathrm{ACh}$ and $\mathrm{HoCh}$. In sum, HoCh appeared to function as a false transmitter precursor in mouse soleus.

AHoCh produced less postsynaptic depolarization than $\mathrm{ACh}$, although $\mathrm{HoCh}$ itself at $50 \mu \mathrm{M}$ had no postsynaptic effect. In cholinesterase-inhibited preparations (see Materials and Methods), the end-plate depolarization produced by $7 \mu \mathrm{M} \mathrm{AHoCh}$ was $3.8 \pm 0.4 \mathrm{mV}$ (13 fibers) and that produced by $7 \mu \mathrm{M} \mathrm{ACh}$ was $25.4 \pm 3.3 \mathrm{mV}$ (14 fibers; examples in Fig. $3 B$ ).

\section{Physiological assay of transmitter turnover}

To estimate the rate of turnover of transmitter during long tetani, replacement of ACh by a false transmitter was indirectly assessed by the progressive reduction in epp amplitude during tetani with and without added $\mathrm{HoCh}$.

Incubation of curarized muscles in solutions containing HoCh for at least $60 \mathrm{~min}$ had no effect on epp amplitudes measured at a stimulation frequency of $0.5 \mathrm{~Hz}$ (Table 1, row 2). However, decline in epp amplitude during $10 \mathrm{~min}$ of indirect stimulation at $10 \mathrm{~Hz}$ was significantly greater in the presence of $\mathrm{HoCh}$ and curare than in curare alone, and this was more so in old muscles (Figs. 2, 4). Similar results were obtained either by recording from individual muscle fibers throughout the period of stimulation (Figs. 2 and 4, open bars) or from a larger epp sample obtained by recording epp's from several end plates at $0.5 \mathrm{~Hz}$ before and after stimulation (Fig. 4, shaded bars; Table 1 for absolute values).

The time courses of the changes in epp amplitude during and after stimulation in curare and in curare with $\mathrm{HoCh}$ are shown in Figure $2 A$ and $B$. In order to compare the effects of these conditions, the values at each time point were normalized by dividing the value in $\mathrm{HoCh}$ by that in curare alone, where the values in curare and $\mathrm{HoCh}$ were themselves expressed as a percentage of the $0.5 \mathrm{~Hz}$ control epp amplitudes. Expressed in this manner (Fig. 2C), the rate of decline of epp amplitude produced by $\mathrm{HoCh}$ was much greater in old than in young animals. After the 10 min tetani (Fig. $2 C$ ), there was only a slight further decrease in young animals and no change in old animals; therefore, samples of epp's obtained in the 5-10 min after the tetanus were of similar amplitude to those obtained in the latter part of the tetanus.

Table 1. Effect of HoCh (0.05 mM) on epp amplitude in young and old soleus muscles before and after stimulation at $10 \mathrm{~Hz}$ for $10 \mathrm{~min}$ followed by $0.5 \mathrm{~Hz}$ for $10 \mathrm{~min}$

\begin{tabular}{|c|c|c|}
\hline & \multicolumn{2}{|l|}{ epp amplitude (mV) } \\
\hline & Young & Old \\
\hline Curare only, before stimulation & $2.94 \pm 0.19(57 / 7)^{a}$ & $4.59 \pm 0.24(78 / 9)$ \\
\hline Curare and $\mathrm{HoCh}$, before stimulation & $2.84 \pm 0.14(84 / 9)^{a}$ & $4.28 \pm 0.29(52 / 6)$ \\
\hline Curare and $\mathrm{HoCh}$, immediately after stimulation & $1.23 \pm 0.07(79 / 9)$ & $1.29 \pm 0.10(52 / 7)$ \\
\hline $\begin{array}{l}\text { After } 15-35 \mathrm{~min} \text { recovery in curare and } 0.1 \mathrm{~mm} \\
\text { choline }\end{array}$ & $2.34 \pm 0.19(41 / 5)$ & $2.90 \pm 0.27(36 / 5)$ \\
\hline $\begin{array}{l}\text { Curare and } \mathrm{HoCh} \text {, ratio (after)/(before } \\
\text { stimulation) for each muscle }{ }^{b}\end{array}$ & $0.44 \pm 0.05(8)^{a}$ & $0.29 \pm 0.02(6)$ \\
\hline
\end{tabular}

Values are given as means \pm SE (number of fibers/number of muscles) except for bottom row (see footnote $b$ ).

a Young and old values significantly different, $p<0.01$.

${ }^{b}$ Ratio per muscle calculated from groups of epp's from 5-10 fibers obtained before and after the $10 \mathrm{~Hz}$ tetanus. Data are overall mean ratios of several muscles (number given in parentheses). 


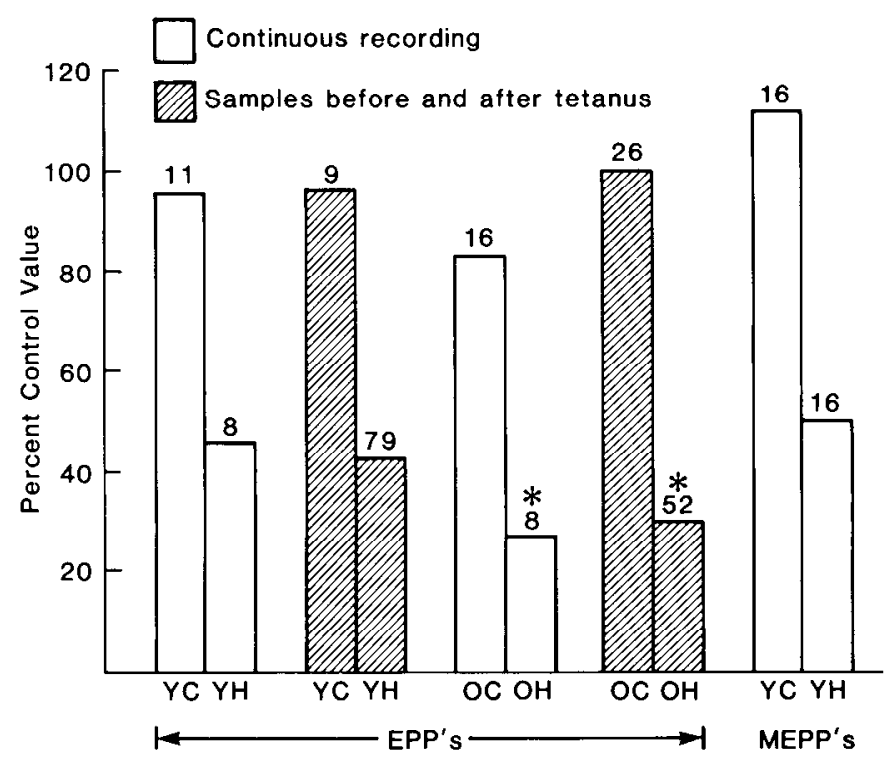

Figure 4. Effect of 6000 stimuli at $10 \mathrm{~Hz}$ on the amplitude of evoked epp's and spontaneous mepp's. Bars represent the percentage change of the amplitude, posttetanus/pretetanus. Open and shaded bars are, respectively, recordings made continuously in single fibers and in multiple fibers before and after $10 \mathrm{~Hz}$ stimulation. Numbers above each bar are the number of muscle fibers sampled. If the numbers sampled were different before and after the tetanus, the lower value was used. Abbreviations: $Y$, young; $O$, old; $H$, tetani in presence of $\mathrm{HoCh}$ and curare; $C$, tetani in curare without $\mathrm{HoCh}$. Asterisks indicate significantly greater reduction in HoCh $(p<0.05)$ in old than in young mice. Tetanic reduction of epp or mepp amplitude in $\mathrm{HoCh}$ was always significantly different from that in the absence of $\mathrm{HoCh}$.

As anticipated from a previous study of false transmitters at the neuromuscular junction (Colquhoun et al., 1977), the gradual decrease in epp amplitude during stimulation in the presence of $\mathrm{HoCh}$ was due to a decrease in quantum size rather than a decrease in the number of quanta released per nerve impulse. Evidence for this was provided by 2 different experimental observations. First, the quantity $1 /(\mathrm{CV})^{2}$, where $\mathrm{CV}$ is the coefficient of variation of epp amplitude, was calculated for epp's at the beginning and end of $10 \mathrm{~Hz}$ stimulation in each fiber. A change in quantum content should be reflected in a change in $1 /(\mathrm{CV})^{2}$ (e.g., Cull-Candy et al., 1980), but the ratio of $1 /(\mathrm{CV})^{2}$ before and after the tetanus was not significantly different from unity (Table 2). Second, mepp's were recorded before and after $10 \mathrm{~min}$ of stimulation at $10 \mathrm{~Hz}$ in uncurarized young soleus muscles (Fig. 4). In the absence of HoCh there was no difference between mepp amplitude before and after stimulation, whereas in the presence of $\mathrm{HoCh}$, the percentage reduction in mepp amplitude after a $10 \mathrm{~min}$ tetanus was similar to the posttetanic percentage reduction of epp amplitudes (recorded in curare and HoCh) (Fig. 4). Finally, amplitude histograms (not shown) indicated that average mepp diminution after nerve stimulation in $\mathrm{HoCh}$ reflected a shift in the entire population rather than the appearance of a bimodal pattern (Large and Rang, 1978b).

\section{Equilibrium epp amplitudes during long-term stimulation}

In tetani lasting $10 \mathrm{~min}$ in the presence of $\mathrm{HoCh}$, a steady-state reduction was not attained in young animals (Fig. 2C). Therefore, in order to estimate the final level of epp amplitude when essentially all released transmitter was in the form of $\mathrm{AHoCh}$, tetani were continued until steady-state values were attained. Stimulation up to $45 \mathrm{~min}$ and continuous recording from single fibers in young soleus showed that, both in curare alone ( 5 fibers, 5 muscles) and in the presence of HoCh ( 5 fibers, 5 muscles),
Table 2. Ratio of $1 /(\mathrm{CV})^{2}$ of epp's recorded from young and old soleus muscles at the beginning and end of $10 \mathrm{~min}$ trains at $10 \mathrm{~Hz}$

\begin{tabular}{lll} 
& \multicolumn{1}{l}{$(\mathrm{CV})^{2}$} & \\
\cline { 2 - 3 } epp conditions & Young & Old \\
\hline Curare only & $0.85 \pm 0.12(12)$ & $1.01 \pm 0.16(16)$ \\
Curare + HoCh & $0.89 \pm 0.13(8)$ & $0.86 \pm 0.07(5)^{a}$
\end{tabular}

Values are given as means \pm SE with number of muscle fibers in parentheses. No ratio was significantly different from unity.

a Three values were excluded because final epp mean amplitudes fell below 0.2 $\mathrm{mV}$ so that baseline noise would cause large errors in the estimate of $1 /(\mathrm{CV})^{2}$.

no further decrease in epp amplitude occurred after 20-25 min (Fig. $5 A$ ). The plateau value of epp reduction due to $\mathrm{HoCh}[(\%$ reduction in $\mathrm{HoCh}) /(\%$ reduction in curare alone $)]$ was at a value of $20 \%$ initial amplitude. Therefore, we conclude that arrival at this final tetanic epp amplitude in the presence of $\mathrm{HoCh}$ signifies complete replacement of releasable ACh by $\mathrm{AHoCh}$.

The half-decay time of epp's before, during, and after stimulation was measured in several muscles, but, in contrast to results reportcd for monocthylcholine (Colquhoun et al., 1977), no effect of HoCh could be detected within the limits of resolution of our method ( $\pm 0.1 \mathrm{msec}$ per epp). For example, in young soleus muscles in $\mathrm{HoCh}$, the half-decay time was $0.82 \pm$ $0.03 \mathrm{msec}(n=36)$ before stimulation and $0.87 \pm 0.03 \mathrm{msec}$ $(n=32)$ after stimulation.

\section{Recovery after long tetani}

In a few experiments, epp's were recorded after muscles had been allowed to recover in $0.1 \mathrm{~mm}$ choline for 15-25 min (Table 1). At that time, in both young and old muscles, the absolute epp amplitude had recovered to about twice that obtained at the end of the tetanus in HoCh. However, in old soleus muscles, perhaps because of the greater tetanic depression, the absolute amplitudes of the epp had recovered to $68 \%$ of control, whereas in young soleus, the recovery was $82 \%$ complete. This indicates that choline largely reverses the effect of HoCh.

\section{Discussion}

\section{Age and tetanic transmitter release}

In curarized old edl muscles, the tetanic rundown of epp amplitude was only slightly greater and recovery only slightly less than in young muscle. Indeed, there was no difference in the percentage decay of the first 50 epp's, and it is likely that in vivo, the burstlike firing of this phasic muscle does not even last this long (Hnik et al., 1978). In soleus muscles, the relative rundown and recovery were identical in young and old muscles for trains of 1200 pulses, and again only slightly (ca. 10\%) different during trains of 6000 impulses. Since control epp amplitudes are nearly 2-fold larger in old muscles (Banker et al., 1983), it is clear that the safety factor is not compromised in old muscles. Rather, output far exceeds that which would be just necessary to compensate for the slightly greater tetanic decline. An increased tetanic output of ACh has also been measured with biochemical techniques in diaphragm muscle of aged rats (Smith, 1984), but in aged rat hippocampus, the synapses showed a more rapid tetanic exhaustion than in young animals (Landfield et al., 1978). However, other factors (e.g., lower initial safety factor) may dominate the net outcome of tetanic stimulation in the brain.

\section{HoCh as a neuromuscular false transmitter}

In superior cervical ganglion, brain synaptosomes, and electromotor synapses, HoCh is taken up, acetylated, and released as a false transmitter (Collier and Kwok, 1982; Luqmani et al., 


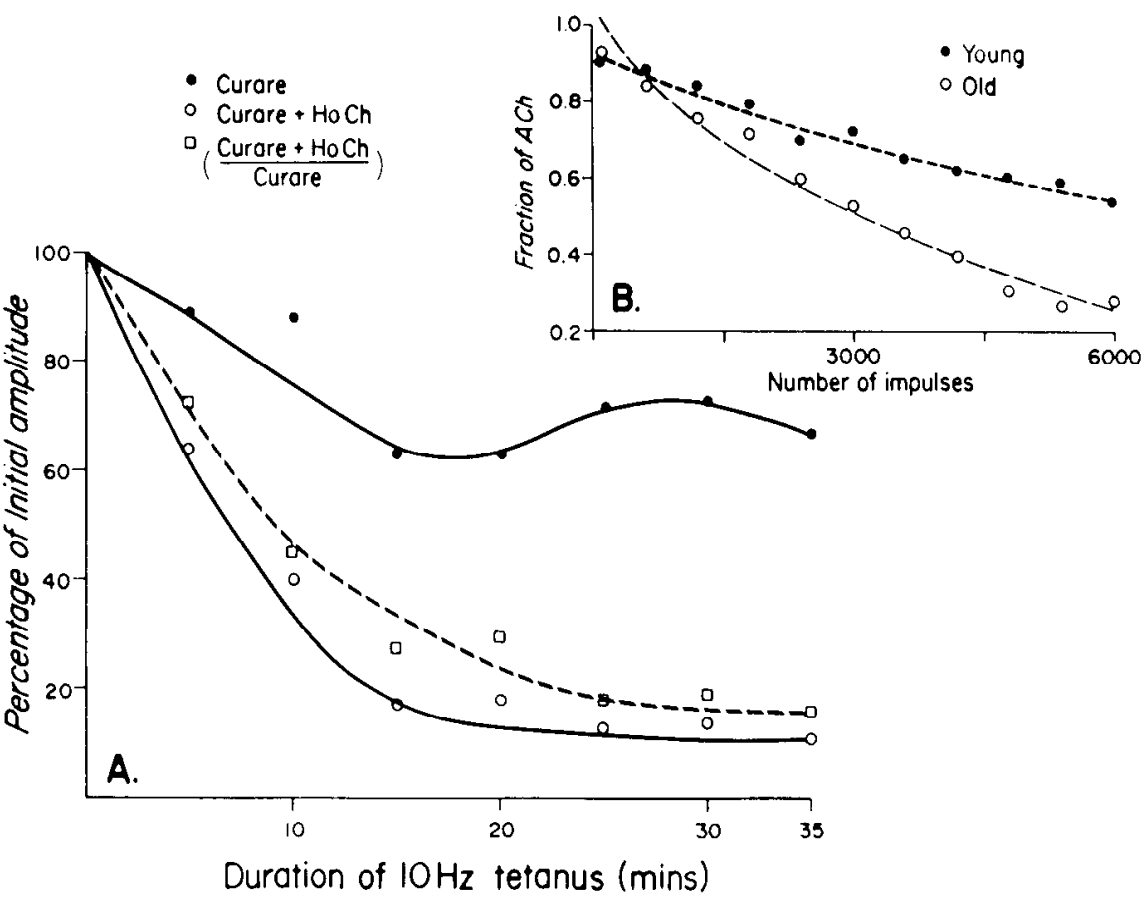

1980). The tracer studies reported here were entirely consistent with similar processing of $\mathrm{HoCh}$ in soleus neuromuscular junctions. Our physiological studies also confirmed a similarity in the conditions of uptake and release to those of a different false transmitter precursor, monoethylcholine, which was extensively investigated in rat diaphragm (Colquhoun et al., 1977; Large and Rang, 1978a, b). In both cases, the acetylated false transmitter did not appear in quantally released transmitter (as evidenced by mepp or epp amplitude) during incubation in the precursor unless the preparation was stimulated. Unlike acetylmonoethylcholine, the release of $\mathrm{AHoCh}$ did not result in a shorter epp decay time constant, possibly due to the long membrane time constant in mouse soleus, $0.77 \mathrm{msec}$ (Banker et al., 1983). Voltage-clamp analysis (Colquhoun et al., 1977) would be necessary to determine whether end-plate current decays more rapidly with $\mathrm{AHoCh}$ than $\mathrm{ACh}$.

Several lines of evidence indicated that reduction of epp or mepp amplitude during tetani in the presence of $\mathrm{HoCh}$ was a valid measure of the fractional contribution of $\mathrm{AHoCh}$ to total transmitter release. First, simple incubation with $\mathrm{HoCh}$ had no effect on mepp or epp amplitude, so that a postsynaptic effect is unlikely. Second, at the end of a 6000 pulse tetanus without HoCh, there was no decrease in mepp amplitude, but in the presence of $\mathrm{HoCh}$, posttetanic mepp and epp amplitudes were both reduced to about the same extent. Thus, reduction of epp amplitude was largely attributable to diminished quantum size rather than reduced quantal content. Third, despite reduction in epp amplitude at the end of the tetanus, the CV of epp amplitude was essentially unchanged, indicating no substantial change in number of quanta released. Fourth, the reduction in epp amplitude cannot be explained by a lower rate of choline (or HoCh) uptake in old muscles, because in curarized preparations, rundown of epp amplitudes during long tetani (which would reflect choline uptake and acetylation) was similar in young and old junctions. Fifth, it is possible that $\mathrm{HoCh}$ acted like hemicholinium to block choline reuptake or that it prevented charging of quanta with $\mathrm{ACh}$, thereby reducing quantal size. However, this type of inhibition yiclds an cventual cxtinction of mepp or epp amplitude in the course of long tetani (Elmqvist and Quastel, 1965), but we observed a reduction of epp amplitude to a new plateau (Fig. $5 A$ ), as also noted by previous workers using monoethylcholine (Colquhoun et al., 1977). Thus, the most plausible explanation for the decline of epp amplitude during tetani in the presence of $\mathrm{HoCh}$ (relative to that in the absence of $\mathrm{HoCh}$ ) is that the component quanta have the same number of false plus true transmitter molecules but that the postsynaptic effect of $\mathrm{AHoCh}$ is much smaller than that of $\mathrm{ACh}$, as was shown directly.

\section{Transmitter turnover in young and old neuromuscular junctions}

The most significant finding in the present report was the substantially greater transmitter turnover in old compared to young soleus neuromuscular junctions. This result, manifested by the faster replacement of ACh by AHoCh in tetanized aged junctions, is qualitatively independent of the turnover model adopted. However, the model proposed below does provide a quantitative estimate of change in turnover with age and its relation to quantal content and store size.

Choosing the model of Large and Rang (1978a) to interpret the data on the rundown of epp amplitude due to replacement of $\mathrm{ACh}$ by $\mathrm{AHoCh}$, the data in Figure $2 \mathrm{C}$ can be expressed on a transformed scale so that an epp that is $20 \%$ of initial amplitude has zero fractional $\mathrm{ACh}$ content (i.e., $100 \% \mathrm{AHoCh}$ ). Thus, the fractional contribution of $\mathrm{ACh}$ to epp amplitude is:

$$
\left[100 \times\left(\mathrm{epp}_{\mathrm{h}+\mathrm{c}} / \mathrm{epp}_{\mathrm{c}}\right)-20\right] / 80
$$

where $e p p_{c}$ and $e p p_{h+c}$ refer to amplitude in curare, or curare + $\mathrm{HoCh}$, respectively. Finally, the abscissa was changed from time to number of impulses at $10 \mathrm{~Hz}$. The transformed data from Figure $2 C$ were fitted to an exponential (broken line in Figure $5 B, r=0.98$ for young and 0.99 for old muscles as a measure of goodness to fit) with rate constants of $-9.4 \times 10^{-5}$ and $-22.2 \times$ $10^{-5}$ impulses $^{-1}$ for young and old junctions, respectively.

It is assumed that the amount of ACh released per impulse ( $N=$ no. of impulses) is proportional both to the amount of ACh remaining in the releasable pool as well as to the ratio of the quanta relcased per impulse $(m)$ to the total available quanta $(M)$ in a steadily replenished pool, with both $m$ and $M$ assumed constant. The first assumption is only approximately true (Large 
and Rang, 1978a, b). When the number of impulses is large, a continuous approximation gives

$$
\frac{d(\mathrm{ACh})}{d N}=\frac{m}{M}(\mathrm{ACh})
$$

and

$$
\frac{\mathrm{ACh}_{N}}{\mathrm{ACh}_{\mathrm{o}}}=\exp \left(\frac{-m N}{M}\right)
$$

where $\mathrm{ACh}_{N} / \mathrm{ACh}_{\mathrm{o}}$ is the fraction of $\mathrm{ACh}$ remaining in the releasable pool of quanta after $N$ impulses, i.e., this is equal to the value of expression (1). When this fraction equals $e^{-1}, M$ can be calculated since $m$ and $M$ are known. From the curves in Figure $5 B, \mathrm{ACh}_{N} / \mathrm{ACh}_{\circ}$ declines to $e^{-1}$ in 10,584 and 4482 impulses in young and old muscle, respectively. Because the rate constant equals $-m / M$ (the ratio of average quantal release per impulse to number of quanta in the releasable pool), one can estimate the relative contribution of each parameter to the altered value in old soleus muscles. Thus, the ratio of rate constants, old/young $=2.4$ should equal $\left(m_{\mathrm{o}} / m_{\mathrm{y}}\right) /\left(M_{\mathrm{y}} / M_{\mathrm{o}}\right)$, where subscripts " $y$ " and "o" signify young and old. The plateau epp amplitudes during 2 or $20 \mathrm{~Hz}$ tetani in curarized preparations give values of $m_{\mathrm{o}} / m_{\mathrm{y}}=1.7$ (Table 2 in Banker et al., 1983). Thus, the greater transmitter output per impulse in old junctions accounts for more than half of the greater turnover, and a diminished pool size $\left(M_{\mathrm{o}} / M_{\mathrm{y}}=1.7 / 2.4=0.7\right)$ must account for the remainder. In fact, the number of vesicles per unit area of nerve terminal in old mouse soleus muscle was about $31 \%$ that in young junctions (Fahim and Robbins, 1982). The discrepancy between the physiologic and the ultrastructural results may have arisen from fixation effects in old junctions (Fahim and Robbins, 1985) or from the distinct possibility that not all vesicles counted are releasable.

It must be emphasized that the fundamental result that transmitter turnover is greater in old than young soleus junctions does not critically depend either on the exact value of steadystate epp tetanic depression in $\mathrm{HoCh}$ used to compute the rate constants nor on the validity of the single-compartment model. If steady-state epp reductions duc to $\mathrm{HoCh}$ are assumed to vary from 64 to $80 \%$, the computations still yield old/young ratios of rate constants of about 2-3. In addition, purely empirical linear or exponential curve-fits to the time course of epp tetanic depression due to $\mathrm{HoCh}$ both show significantly greater slopes or rate constants in old than in young soleus muscles.

Another implication of these turnover studies is that increased quantal release in old soleus junctions is not simply the result of a larger or more branched junction, as proposed for rat diaphragm (Smith, 1984). Were this the case, increased transmitter output would not be accompanied by an increase in the rate constant of turnover, as observed here since the ratio $\mathrm{m} / \mathrm{M}$ would stay constant as more terminal boutons or branches were added, i.e., both $m$ and $M$ would go up proportionately. Indeed, quantitative nerve terminal staining in young and old mouse soleus showed only slight terminal enlargement in old muscles (Robbins and Fahim, 1985).Thus, the increased transmitter re- lease in aged soleus muscle junctions derives from a different mechanism, such as an alteration in active zone density, ionic flux, or concentration or buffering of calcium in the nerve terminal. These conclusions probably also apply to the mouse edl muscle, in which a small age-related enlargement of nerve terminal area (Robbins and Fahim, 1985) also does not account for the observed increase in transmitter release (Banker et al., 1983). However, the generality of these conclusions in the case of other aging muscles remains to be determined.

\section{References}

Banker, B. Q., S. S. Kelly, and N. Robbins (1983) Neuromuscular transmission and correlative morphology in young and old mice. $\mathbf{J}$. Physiol. 339: 355-375.

Collier, B., and Y. N. Kwok (1982) The uptake and metabolism of choline analogues by cholinergic nerve terminals. In Neurotransmitter Interaction and Compartmentation, H. F. Bradford, ed., Plenum, New York.

Colquhoun, D., W. A. Large, and H. P. Rang (1977) An analysis of the action of a false transmitter at the neuromuscular junction. $J$. Physiol. 266: 361-395.

Cull-Candy, S. G., R. Miledi, A. Trautmann, and O. D. Uchitel (1980) On the release of transmitter at normal, myasthenia gravis and myasthenic syndrome affected human end-plates. J. Physiol. 299: 621638.

Elmqvist, D., and D. M. J. Quastel (1965) Presynaptic action of hemicholinium at the neuromuscular junction. J. Physiol. 177: 463-482.

Fahim, M. A., and N. Robbins (1982) Ultrastructural studies of young and old mouse neuromuscular junctions. J. Neurocytol. 11: 641-656.

Fahim, M. A., and N. Robbins (1985) Transmitter release and ultrastructure of young and old mouse neuromuscular junctions in low calcium solutions. Soc. Neurosci. Abstr. 11.

Fischbach, G. D., and N. Robbins (1969) Changes in contractile properties of disused soleus muscles. J. Physiol. 201: 305-320.

Gertler, R. A., and N. Robbins (1978) Differences in neuromuscular transmission in red and white muscles. Brain Res. 142: 160-164.

Hnik, P., S. Kasicki, Z. Afelt, R. Vejsada, and I. Krekule (1978) Chronic polyelectromyography in awake unrestrained animals. Physiol. Bohemoslov. 27: 485-492.

Landfield, P. W., J. L. McGaugh, and G. Lynch (1978) Impaired synaptic potentiation processes in the hippocampus of aged, memorydeficient rats. Brain Res. 150: 89-101.

Large, W. A., and H. P. Rang (1978a) Factors affecting the rate of incorporation of a false transmitter into mammalian motor nerve terminals. J. Physiol. 285: 1-24.

Large, W. A., and H. P. Rang (1978b) Biomodal shift in variability of transmitter quanta released during incorporation of a false transmitter into cholinergic nerve terminals. J. Physiol. 285: 25-34.

Luqmani, Y. A., G. Sudlow, and V. P. Whittaker (1980) Homocholine and acetylhomocholine: False Iransmilters in the cholinergic electromotor system of Torpedo. Neuroscience 5: 153-160.

Martin, A. R. (1955) A further study of the statistical composition of the end-plate potential. J. Physiol. 130: 114-122.

Robbins, N., and G. D. Fischbach (1971) The effect of chronic disuse of rat soleus neuromuscular junction on pre-synaptic function. $J$. Neurophysiol. 34: 570-578.

Robbins, N., and M. A. Fahim (1985) Progression of age changes in mature mouse motor nerve terminals and its relation to locomotor activity. J. Neurocytol. 14: 1019-1036.

Smith, D. O. (1984) Acetycholine storage, release, and leakage at the neuromuscular junction of mature adult and aged rats. J. Physiol. 347: $161-176$. 